\title{
A FENOMENOLOGIA-ONTOLÓGICA-ESTRUTURAL DE ARMANDO CORRÊA DA SILVA: VARIAÇÕES SOBRE O TEMA \\ The ontological-structural-phenomenology of Armando Corrêa da Silva: variations on the theme
}

\section{Werther Holzer}

RESUMO

O que proponho apresentar neste texto é um diálogo com a obra de Armando Corrêa da Silva a partir de dois textos publicados "Fenomenologia e Geografia" e "A Aparência, o Ser e a Forma" além de material inédito que ele me disponibilizou por ocasião de meu ingresso como doutorando em Geografia Humana da Universidade de São Paulo. Inspirado na música, onde um tema pode ser retrabalhado em muitas variações, tomarei alguns textos e os submeterei a variações imaginárias, segundo uma intuição fenomenológica. O que pretendo desvelar é o Ser da Geografia a partir de uma leitura parcial da obra de Armando Corrêa da Silva, centrada em sua ontologia analítica. Nela a geografia é definida como ideologia do cotidiano, o ser é tomado como ideia concreta e abstrata. É na singularidade, que se relaciona à particularidade e à universalidade, que o concreto se abre ao existir, como experiência, atividade, reflexão.

Palavras-chave: Fenomenologia. Ser. Forma. Lugar.

\section{ABSTRACT}

What I propose in this paper is to present a dialogue with the work of Armando Correa da Silva from two published texts - "Phenomenology and Geography" and "The Appearance, Being and Form" - in addition to new material he provided me during my time as a doctoral student in Human Geography at the University of São Paulo. Inspired by music, a theme which can be reworked in many variations, I take some texts and will submit them to imaginary variations, from a phenomenological intuition. What I want is unveiling the Being of Geography from a partial reading of the work of Armando Correa da Silva, with focus on your analitic ontology. The geography is defined as the ideology of everyday life, the being is taken both as a concrete and as abstract idea. Is the singularity, that relates the particularity and universality, that the concrete opens to exist, such as experience, activity, reflection.

Keywords: Phenomenology. Being. Form. Place.

1 Professor da Escola de Arquitetura e Urbanismo da Universidade Federal Fluminense. werther.holzer@uol.com.br.

$\gtrsim$ Escola de Arquitetura e Urbanismo, Universidade Federal Fluminense. Rua Passo da Pátria, 156, São Domingos, Niterói, RJ. $24210-240$. 
A fenomenologia-ontológica-estrutural de Armando Corrêa da Silva: variações sobre o tema Werther Holzer

O que proponho apresentar neste texto é um diálogo com a obra de Armando Corrêa da Silva a partir de dois textos publicados "Fenomenologia e Geografia" e "A Aparência, o Ser e a Forma" -, além de material inédito que ele me disponibilizou por ocasião de meu ingresso como doutorando em Geografia Humana da Universidade de São Paulo.

Este diálogo procura recuperar algumas questões que discutimos ao longo dos quatro anos em que fui seu orientando. Não foi um diálogo fácil, não que não houvesse interlocução, tínhamos o interesse comum pela epistemologia da geografia, mas os aportes que buscávamos eram bastante diversos. Por este motivo estas eram conversas bastante produtivas, acredito que para ambos.

Este diálogo, interrompido em novembro de 1998, quando defendi minha tese, não pode ser retomado. Uma versão deste está na minha tese, em seus fundamentos teóricos que discutem a geografia como ciência das essências a partir de um referencial fenomenológico, baseado principalmente nas ideias de Merleau-Ponty e de Heidegger. O que retomo aqui é uma pergunta que Armando (vou manter essa intimidade ao longo do texto pois a considero necessária) me dirigiu inúmeras vezes ao longo dos quatro anos de orientação, e que repetiu durante a defesa: para você o que é o Ser na Geografia?

Evidentemente esta questão tinha como referência à fenomenologia e a geografia enquanto ciência das essências. Dirigia-se ao meu aporte teórico. Sempre me esquivei em respondê-la, porque Armando utilizava-se da fenomenologia a partir de Sartre, procurando uma ponte com o marxismo a partir de filósofos como Luckács. Sempre tive dificuldades em visualizar estas pontes, existe uma distância ontológica entre os aportes marxista e fenomenológico, ou seja, Armando e eu falávamos de Seres diferentes.
Mas aqui está uma oportunidade, dez anos depois de deixar Armando falar sobre o Ser para a Geografia. Não é fácil penetrar no pensamento teórico de Armando, porque seu texto é curto e denso, aparentemente fragmentado. O fato é que ele procurava esgotar os conceitos que pretendia abordar. Deixarei que ele nos fale sobre seus motivos, a partir de um texto produzido em 19/11/1993, intitulado "O Imaginário, a Memória e a Representação":

O cotidiano da universidade é, de certo modo, limitador, específico. [...] daí, que o ideal é fazer com que o trabalho de pesquisa não se torne mais uma tarefa desgastante. [...] Então é preciso livrar-se das citações, do conhecimento excessivamente padronizado, das obrigações burocráticas cerceadoras e soltar o pensamento e a ação. [...] Fazer isso é colocar-se como um sujeito em construção e lidar com a objetividade imaginada. (SILVA, 1993)

Não farei mais citações ao longo deste texto. Inspirado na música, onde um tema pode ser retrabalhado em muitas variações, tomarei alguns textos e os submeterei a variações imaginárias, segundo uma intuição fenomenológica. O que pretendo desvelar é o Ser da Geografia a partir de uma leitura parcial da obra de Armando Corrêa da Silva.

Inicio a discussão a partir do texto "Geografia e Fenomenologia". Armando foi dos primeiros a se debruçar sobre este tema no Brasil. Tinha como referência Tuan e Buttimer, para o lugar do ponto de vista do sujeito; Tonino Bettanini, um autor desconhecido por nossa geografia, para o espaço do corpo, da vida, vivido; Paul Claval para o território subjetivo. Três matrizes estão aqui presentes: a humanista (fenomenológica); a do Espaço Vivido: a da Geografia Cultural. As duas últimas segundo uma tradição francesa.

Para Armando a contribuição da fenomenologia, a partir da análise do que discutiam os autores citados acima, seria a de retornar a 
A fenomenologia-ontológica-estrutural de Armando Corrêa da Silva: variações sobre o tema Werther Holzer

subjetividade como tema da ciência, a partir da própria ideia ou da existência.

Ideia é um termo fundamental para a construção da fenomenologiaontológica-estrutural, como proposta em "A Aparência, o Ser e a Forma". Este texto trata de um salto epistemológico no pensamento/ obra de Armando: ele procura desenvolver um método onde o espaço, enquanto objeto de uma geografia renovada, possa ser reencontrado.

Este espaço, segundo Armando, era de ocorrência e de manifestação na Idade Moderna. Passou na Sociedade Pós-Moderna a ganhar importância, em si, como produto e como produção. Para Armando esta constatação apontava apenas na direção da explicitação ontológicao?-analítica do método (para a geografia).

A ideia (abstrata), a ideia do nada, um "nada" sartreano, supõe uma abstração. Neste conceito está a chave, segundo Armando, para unir os aportes fenomenológico e marxista. A abstração em si mesma é um objeto. Ela se põe ante a mente no vazio, mas este vazio é tomado como um aspecto do real concreto em si. A ideia do nada nasce da praticidade do mundo (diria, da facticidade), e está contida na abstração.

A abstração, então, não se relaciona com o mundo da física, mas com as escolhas - a intencionalidade.

Em "Fenomenologia e Geografia" Armando conceitua a fenomenologia de Husserl como um "novo modo de ver". Uma concepção científica do mundo voltada para a filosofia como "ciência das ciências", tratando de uma ciência nova, alimentada pelos problemas colocados pela geometria não-euclidiana.

A principal crítica da fenomenologia seria contra o objetivismo cientificista do positivismo, que elimina o sujeito da análise. Husserl propõe como método à suspensão do juízo sobre o mundo natural. $\mathrm{O}$ juízo é substituído pela intuição, onde o ser se volta para as coisas a partir do fluxo do vivido, da intencionalidade, que é, segundo Armando, a consciência de...

Armando observa que a consciência prática rejeita a ideia abstrata. Da oposição entre a ideia abstrata e a ideia concreta nasce à ideia do projeto e do plano (seria a intencionalidade). Este se refere à consciência técnica, que cria os códigos, que organiza o mundo do homem contemporâneo.

Para Armando esta codificação moderna sobrepõe-se à renascentista, à iluminista, à romântica, no momento em que, historicamente, estão mortas. Esta contradição abriria infinitas possibilidades de indeterminação. No limite esta indeterminação passa a ser aleatoriamente determinada (como código), ultrapassando então o "sistema de coordenadas da subtotalidade geográfica", colocando a geografia como modo prisioneiro da história.

Geografia como subtotalidade, eu diria como ciência das essências, como região fenomenológica, mas Armando está referenciado também na análise marxista. Então a geografia é identificada como uma ideologia do cotidiano, diria que se refere ao mundo vivido, ou como preferia Wright, todas as pessoas são geógrafos. Ideologia expressa pela espacialidade do valor relacional contido no real. Esta espacialidade é, ao mesmo tempo, essencialidade desse real e sua manifestação externa. A percepção - aquilo que se vê, define o significado da geografia pela particularidade e pela forma, ou seja, pelo que se apresenta no fluxo da existência como configuração do espaço e movimento nesse espaço.

O que Armando pretendia era determinar um método para se estudar esta subtotalidade. Este método deveria se afastar da consciência técnica - que contém um saber específico que se esgota com a função. Ela está presa aos modos prático-inertes, como trabalho morto, ou seja, ela se refere a artefatos, a coisas, que já foram consumidas. A 
A fenomenologia-ontológica-estrutural de Armando Corrêa da Silva: variações sobre o tema Werther Holzer

consciência teórica é que vai dar a primeira significação, como trabalho vivo, articulando causas que exprimem a funcionalidade. $\mathrm{O}$ projeto articula as ideias abstratas e concretas como teoria científica.

Ao investigar a fenomenologia Armando se deteve nas suas origens enquanto teoria das aparências (LAMBERT, 1764); como representação enquanto sinônimo de aparência (Kant); como história das etapas sucessivas das aproximações e das oposições (Hegel). Mas como "novo modo de ver" husserliano ela é uma teoria da existência que pergunta: pode a consciência vir de dentro? O que é a consciência? Existem objetivamente estes fenômenos? Ela se opõe a uma teoria do conhecimento marxista-leninista, voltada para uma teoria das ideologias, que supõe a consciência vinda de fora.

O marxismo trata da forma e do conteúdo, construindo um modelo que vai do abstrato ao concreto. A fenomenologia trata da forma aparente e da forma real, ela desenvolve um método que descreve o fenômeno, o "objeto" enquanto essência captada pela "wissenchau", a intuição essencial. Mais tarde Merleau-Ponty e outros fenomenólogos franceses, seguindo os passos de Husserl em suas últimas publicações, onde a essência é associada a "lebenswelt", o mundo vivido, recolocando as essências na existência e procurando compreender o homem em sua facticidade.

Segundo Armando o método é pura abstração, manuseio da forma, num movimento autônomo que a consciência capta como certeza na relação. A verdade é o instante que a história prolonga. A representação, ou imagem decodificada é o modo de aprender o real, que só se torna possível através do pensamento teórico. Ela dá concretude à ideia.

O teórico é a ideia abstrata informada pelo raciocínio em movimento, na intrasubjetividade e na intraobjetividade. Eu diria na intersubjetividade, na intenção que se volta para as coisas e as identifica a partir de suas essências.
O que buscava Armando na fenomenologia?

Uma unidade em torno do ser humano. A dimensão ôntica do método dada pela fragmentação do real e a mente dividida. Diria dada pela facticidade humana. Ele procura uma teoria do cotidiano que supõe a objetividade construída pelo trabalho criativo, que indica possibilidades e probabilidades novas: a objetividade analítica defrontada com a questão da humanidade.

Na fetichização do mundo presente o ser é objeto, mas como o objeto pensado é o objeto dado, neste caso o espaço transpassa o objeto, o envolve, apresenta-se como campo de força a ele inerente: transporta consigo espacialidades.

Para a sua compreensão enquanto objeto teórico é necessário à consciência colocar-se como extraterritorialidade, lutar contra a inércia do pensamento concreto, interiorizar: abstrair o concreto como ponto de partida. Defrontar o nada com o mundo da intersubjetividade, colocar em contradição a ideia abstrata e a ideia concreta. Desvelar (permito-me a utilizar o termo de Heidegger) o movimento.

Ao colocar-se a intersubjetividade em movimento evidencia-se o relacional. Segundo Armando este movimento pode ser objetivado pelo trabalho, que coisifica o produto e a mente, opondo-se à idealização do artefato e do ato. A subjetividade se manifesta no ver. Para ultrapassar a aparência é necessário vivenciar o lugar.

Em "OTerritório da Consciência e a Consciência do Território", escrito em 25/04/1993, Armando fala do lugar. Do lugar em si, impossível de ser conhecido, determinação natural expressa através das relações exteriores à ecologia, à sociedade e à cultura. O lugar de ocorrência, já humanizado, implica em estranhamento, separação; ele impõe fronteiras e limites, força o convívio entre os desiguais, configurando o território como ser, estar, ter, haver. O lugar da manifestação, que gera a institucionalização do espaço enquanto território. 
Essas facetas múltiplas do lugar referem-se ao ato, ao vivenciar. Mas, o movimento implica em afastamento, em distância do objeto vivenciado, que é organizado enquanto imagem. Uma imagem que ganha concretude, que representa o lugar, tornando-se um prolongamento do corpo e da mente.

Para Armando no "ver" há que se distinguir três dimensões da objetividade: a imagem abstrata, a experiência e a interiorização. A interiorização do objeto, a partir da experiência, transforma-o m subjetividade-objetivada. Esta mudança na relação entre objeto e sujeito, motiva a ação. O espaço e o tempo não se apresentam separados.

Mas, e o objeto da Geografia?

Não se pode confundi-lo com a coisa morta. É tarefa dos historiadores trazerem-na de volta à vida. A geografia trata do tempo espacial, que não é o tempo histórico, é tempo do percurso. Tratase da relação entre os lugares. A memória alerta para o presente das imagens. As determinações e as indeterminações do passado tornamse as motivações do presente, que aglutina passado e futuro no fluxo do vivido. O desconhecido recupera a visão da aparência, que denota o ser e a forma. A recuperação da visão da aparência é um ver carregado de subjetividade.

O espaço-tempo vivido é uma mediação. A ideia, como abstração, deve ser reposta a partir da ultrapassagem de seu significado empírico.

Para Armando a Geografia Humana já encontrou seu caminho epistemológico. Numa epistemologia da natureza e da sociedade, da tecnologia do período técnico-científico, da organização do espaço e do meio ambiente.

Mas, há um impasse filosófico entre aparência e essência, que é remetida aos filósofos. Armando propõe uma ontologia analítica. Nela a geografia é definida como ideologia do cotidiano, o ser é tomado como ideia concreta e abstrata. É na singularidade, que se relaciona à particularidade e à universalidade, que o concreto se abre ao existir, como experiência, atividade, reflexão.

Resolvida esta questão, poderemos tratar da epistemologia da geografia enquanto forma-linguagem.

Se me permitem, para concluir cito um trecho de um texto escrito por Armando em 25 de janeiro de 1994, intitulado "Excurso sobre as razões da razão científica e o cotidiano", em item denominado "As Razões da Razão Científica": "A crise epistemológica-ontológica não advém da loucura. Ao contrário: o raciocínio, que se apoia no método, na gnoseologia, na teoria do conhecimento e na lógica busca a consistência teórica que repousa nos fundamentos da aparência, do ser e da forma".

Mas, é uma paralogia serena, diversa da dos inventores, que implica no se fazer forma em movimento.

As razões da razão científica geográfica, para além da fantasia, do sonho, da utopia, conduzem o fazer do conhecimento, sem que se desfaçam o inconsciente e o imaginário da "poética do Espaço" de Bachelard.

\section{REFERÊNCIAS}

SILVA, Armando Corrêa da. Fenomenologia e Geografia, Orientação, São Paulo, v. 7, p. 53-56, dez. 1986.

A aparência, o ser e a forma. GEOgraphia, Niterói, ano II, n. 3, p. $7-25,2000$.

Submetido em Outubro de 2013. Aceito em Janeiro de 2014. 